\title{
Prevalence and risk factors associated with headache amongst medical staff in South China
}

Wei Xie ${ }^{1}$, Ruibing $\mathrm{Li}^{2}$, Mianwang $\mathrm{He}^{1}$, Fang $\mathrm{Cui}^{3}$, Tingting $\mathrm{Sun}^{3}$, Jianmei Xiong ${ }^{3}$, Dengfa Zhao ${ }^{1}$, Weinan $\mathrm{Na}^{1}$, Ruozhuo Liu' ${ }^{* *}$ and Shengyuan $\mathrm{Yu}^{1 *}$

\begin{abstract}
Background: A previous study by our team reported the prevalence of primary headache disorders and factors associated with headache among nurses in three hospitals in North China. The aim of this cross-sectional survey was to learn more about how medical nurses in South China were affected by headache. Additionally, we determined the prevalence of headache and measured the impact of headache among doctors in mainland China for the first time.

Methods: Stratified random cluster sampling was used to select 280 physicians and 365 nurses from various departments in four hospitals in Sanya, which is one of southernmost cities in China. Information was collected on demographic data, occupational factors and headache characteristics by using a structured questionnaire.

Results: Among 645 medical staff, $548(85 \%)$ responded (doctors=240, nurses = 308). Among the medical staff, the 1year prevalence of primary headache disorders was $50 \%$, with $25.9 \%$ experiencing migraine and $24.1 \%$ experiencing tension-type headache $(T H H)$. The prevalence of migraine in female doctors was higher than that in female nurses, although this difference was not significant (32.4\% vs. 29.8\%, $P=0.628$ ). Multivariate analysis showed that being female and working in other specialties (Emergency Department \& Radiology Department) remained independent risk factors for migraine in doctors (OR 2.314 and 3.223). In nurses, being married was a risk factor for migraine (OR 3.728), and job titles remained an independent risk factor for migraine and TTH (OR 2.294 and 4.695). Working more than 6 night-shifts per month was associated with an increased prevalence of migraine and TTH in doctors; the same was true in nurses for migraine, but not for $\mathrm{TTH}$.

Conclusion: The prevalence of primary headache disorders in both nurses and doctors is higher than that in the general population in South China. Our study shows that occupation, geography and sex may play an important role. Further, female doctors are more susceptible than female nurses to migraine. The risk factors relevant to headache that were found in this study should provide an important reference for promoting occupational health in medical staff, especially female doctors in China.
\end{abstract}

Keywords: Prevalence, Headache, Migraine, Tension-type headache, Medical staff

\footnotetext{
*Correspondence: liuruozhuo301@163.com; yusy1963@126.com

'International Headache Center, Department of Neurology, the First Medical

Center, Chinese PLA General Hospital, Fuxing Road 28, Haidian District,

Beijing 100853, China

Full list of author information is available at the end of the article
}

(c) The Author(s). 2020 Open Access This article is distributed under the terms of the Creative Commons Attribution 4.0 International License (http://creativecommons.org/licenses/by/4.0/), which permits unrestricted use, distribution, and reproduction in any medium, provided you give appropriate credit to the original author(s) and the source, provide a link to the Creative Commons license, and indicate if changes were made. 


\section{Background}

Few people never experience headache in their lifetime due to the high prevalence of this disorder in the general population throughout the world. The most prevalent headache disorders are migraine and tension-type headache (TTH) [1]. The 2016 Global Burden of Disease (GBD) study established TTH as the third most prevalent condition in the world and migraine as the sixth [2]. A population-based study in China showed that the 1-year prevalence of primary headache disorders was $23.8 \%$ [3], which appears to be much lower than that in other countries and regions. In other Asian countries, the 1-year prevalence of headache disorders ranged from $64 \%$ (India) to $85 \%(\mathrm{Nepal}$ ) [4]. European regional studies showed that $53 \%-75 \%$ of people experienced headache disorders, while the 1-year headache prevalence was $45 \%$ in Ethiopia and 62\% in Zambia [4]. Despite the differences in prevalence in different regions and countries, the socioeconomic impact of headache disorders was similar: The overall lost gross domestic product (GDP) was approximately $1.7 \%$ [4]. Headache can substantially impair quality of life and is ranked sixth among the leading causes of years lived with disability (YLDs) worldwide [5, 6].

Some epidemiological studies have shown that several risk factors, including sex [7], body mass index (BMI) [8], smoking [9], family history [10], and climate [11] might be associated with primary headache disorders. Despite the lower prevalence in China, the risk factors are similar to those reported for other countries [12-14]. In a previous study in North China, we found that the prevalence of primary headache disorders in nurses was significantly higher than that in the general population (45.3\% vs. 23.8\%) [15]. Occupational factors may play a vital role in the pathogenesis of headache. Medical staff, including nurses, confront heavy workloads and experience states of high tension and high intensity for long periods [15]. Therefore, more attention should be paid to the health status of medical staff. In addition to occupation, climate affects the development of headache to varying degrees $[16,17]$. China is a vast country spanning the temperate zone, tropics and subtropics. Hainan is the only province completely within the tropical region. It is located in the southernmost part of China, and Sanya city is located at the southern tip of Hainan. The headache rate of medical staff in this area is not yet available.

In this paper, we sought to provide recent statistics on the prevalence of primary headache disorders in medical staff in South China. Our aims were to update prior prevalence estimates and to identify other factors relevant to headache disorders among medical staff in China, which should be a supplementary extension of "Lifting The Burden" in China.

\section{Methods}

\section{Ethics}

The study protocol was approved by the Ethics Committee of the Chinese PLA General Hospital, Beijing. All patients were informed of the purpose of the study and provided informed consent prior to participating.

\section{Sample and survey}

This is a cross-sectional survey conducted in three tertiary A hospitals (Hainan Hospital of Chinese PLA General Hospital, the Third People's Hospital of Hainan Province and the People's Hospital of Sanya) and one secondary A hospital (the Chinese PLA No. 425 Hospital) in Sanya, South China, from May 2018 to October 2018. We conducted a preliminary survey of one department in each hospital to test epidemiological methods and then adopted a stratified random cluster sampling method. In each hospital, we randomly selected eight clinical departments, from which all doctors and nurses were invited to participate the headache survey. The survey was divided into 2 parts: questionnaires and interviews (face-to-face interviews \& telephone interviews). All those reporting headache were interviewed after their questionnaires were reviewed by neurologists.

\section{Procedure \\ Questionnaires}

Neurologists, who had been systematically trained with The International Classification of Headache Disorders, 3rd edition (ICHD-3) tool and the survey, explained the notes for the questionnaire and answered the participant's questions. Then each participant completed the structured questionnaire to gather demographic data, occupation-related factors and headache characteristics over the previous year. The demographic and headache profile sections of the questionnaire were the same items as used in a Chinese national epidemiology study, and were validated for headache assessment and diagnosis in the general population $[3,15,18]$.

A.The demographic characteristics section: Sex, Age, Ethnicity (Han v.s. Non-Han), Marital Status: Unmarried (including single and divorced people) v.s. Married, Education (College or lower, Bachelor's degree, Master's degree or above), and body mass index (BMI, graded as Underweight, Normal Weight, Overweight, Obese).

B.The occupational characteristics section: Specialty (Internal Medicine, Surgical Department, Others: Emergency Department and Radiology Department), Work Seniority (Doctors: $<7$ years v.s. $\geq 7$ years; Nurses: $<5$ years v.s. $\geq 5$ years; 5 and 7 were the median), Title (Junior, Senior and Advanced. Doctors: Resident, Attending Physician and Deputy Chief Physician or above; Nurses: Nurse, Nurse Practitioner and Nurse-in-charge or above), Work Arrangements (rotational shifts) and Number of Night Shifts (for those performing shift work).

C.The headache profile section (25 questions): Headache Duration, Frequency, Location, Quality, Intensity, Aura, Characteristics of Accompanying Symptoms (Nausea, 
Vomiting, Photophobia and Phonophobia) and The Impact of Physical Activity on Headache, etc. Diagnostic questions began with a headache screening question "Have you had a headache in the last year not related to flu, hangover, cold or head injury?". Those who answered "no" to this question were classified as headache-free. All those reporting headache were invited to interviews after their questionnaires were reviewed. In this questionnaire, trigeminal autonomic cephalalgias (TACs), other primary headache disorders and secondary headaches were not included.

\section{Interviews}

In face-to-face interviews, trained neurologists would confirm the headache diagnosis based on the ICHD-3. Any participant who might have more than one type of headache was instructed to focus on the subjectively most bothersome type (meaning that only one headache type was diagnosed) for purposes of description, diagnosis and prevalence counting. Participants reporting headache occurs 15 or more days/month for more than 3 months were diagnosed with chronic daily headache $(\mathrm{CDH})[1,19,20]$ and questioned if medication-overuse headache $(\mathrm{MOH})$. Neurologists would consider differential diagnoses, and remain alert to other possible diagnosis that raise a need for further examinations: the Red flag mostly to signal cases that might be secondary headache. If necessary, they would perform general and neurological examination.

All the participants were interviewed through telephone, especially for originally headache-free participants and headache participants with ambiguous memories to lower the recall bias.

\section{Statistics}

The statistical analyses were conducted with IBM SPSS (version 23.0). Continuous variables that did not comply with the normal distribution were summarised as medians, and categorical variables were summarised as numbers and percentages. We used Chi-squared to compare distributions of categorical variables between groups, and used Bonferroni correction to adjust the statistical results for multiple comparisons (when the product of the Least Significant Difference $P$-value and the number of comparisons exceeds 1 , the Bonferroniadjusted $P$-value would be set 1.000$)$. Multivariate logistic regression was applied to identify odds ratios (ORs) with $95 \%$ confidence intervals (CIs) for different types of headache according to demographic and occupational characteristics. Statistical significance was set at $P<0.05$.

\section{Results}

Among the 645 medical staff invited to participate, 22 declined to complete the survey, and 75 submitted questionnaires with incomplete or perfunctory responses.
The response rate was $85 \%$. A total of 548 respondents completed the survey (doctors $=240$, nurses $=308$ ). The age ranged from 20 to 60 years, with a median of 28 years (doctors $=31$ years, nurses $=27$ years).

Only 3 respondents were diagnosed with two types of primary headache, and 18 had other headaches, including neuralgia, $\mathrm{CDH}$, and unclassifiable headache. Only 1 nurse was diagnosed with $\mathrm{MOH}$. As the number of people suffering from $\mathrm{CDH}$ and $\mathrm{MOH}$ was low, we did not take these disorders into account.

Table 1 and Fig. 1 showed that among the medical staff, the 1-year prevalence of primary headache disorders was $50 \%$ (95\% CI $45.8-54.2 \%$ ), with $25.9 \%$ (95\% CI 22.2-29.6\%) experiencing migraine and $24.1 \%$ (95\% CI 20.5-27.7\%) experiencing TTH. Both types of primary headache were more prevalent in nurses than in doctors (migraine: $29.2 \%$ vs. $21.7 \%, P=0.045$; TTH: $24.7 \%$ vs. $23.3 \%, P=0.715$ ) (showed in Table 2, Fig. 1). However, by further dividing doctors and nurses into two groups by sex, we found that the group of female doctors had the higher prevalence of migraine than female nurses, although this difference was not significant $(32.4 \%$ v.s. $29.8 \%, P=0.628$ ) (see Table 2 and Fig. 2). The prevalence of both migraine and TTH peaked during middle age (30-39 years) in the nurse and doctor groups but were higher in the former group than in the latter (migraine: $31.4 \%$ vs. $25.2 \%, P=0.168<0.05$; TTH: $29.1 \%$ vs. $24.3 \%, P=0.213<0.05)$. Because there were very few nurses over the age of 40 and none of them had TTH, we did not count them (see Figs. 3 and 4).

Comparisons of the demographic data for medical staff with different types of headaches and non-headache are shown in Table 1. Univariate analysis suggested that age, marital status, ethnicity, education, and BMI were not linked to either of two types of primary headaches.

Comparisons of the occupation-related data between different types of headaches and non-headaches for doctors and nurses are shown in Tables 3 and 4. Specialty did not correlate with any type of headaches in doctors (migraine: internal medicine: $20.3 \%$, surgical department: $19.2 \%$, other specialties: $34.5 \%, P=0.786>0.05$; TTH: internal medicine: $22.5 \%$, surgical department:27.4\%, other specialties: $17.2 \%, P=1.000>0.05$ ) or with TTH in nurses (internal medicine: 26.2\%, surgical department: $22.8 \%$, other specialties: $26.1 \%, P=1.000>0.05$ ). However, internal medicine nurses were less likely to experience migraine than nurses in the surgical department (internal medicine: $21.5 \%$, surgical department: 36.0\%, $P=0.033<0.05$ ). The prevalence of TTH was significantly higher for some nursing roles (nurse: $15.6 \%$, nurse practitioner: $34.0 \%, P<0.001$ ), but this was not observed for doctors (resident: $22.5 \%$, attending physician: $26.6 \%$, deputy chief physician or above: $21.3 \%, P=1.000>0.05$ ). The prevalence of migraine and total headache did not 
Table 1 The demographic characteristics comparisons between different types of headaches and non-headache among medical staff

\begin{tabular}{|c|c|c|c|c|}
\hline \multirow[t]{2}{*}{ Variable } & Non-headache & Total headache & Migraine & TTH \\
\hline & $\mathrm{N}$ & $N(\%) P$ & $\mathrm{~N}(\%)$ Bonferroni $P$ & $\mathrm{~N}(\%)$ Bonferroni $P$ \\
\hline Total & 256 & $292(53.3)$ & $142(25.9)$ & $132(24.1)$ \\
\hline Age & & 0.067 & 0.072 & 0.969 \\
\hline $20-29$ & 140 & 163(53.8) & $82(27.1)$ & $70(23.1)$ \\
\hline $30-39$ & 84 & $109(56.5)$ & $54(28.0)$ & $51(26.4)$ \\
\hline$\geq 40$ & 32 & $20(38.5)$ & $6(11.5)$ & $11(21.2)$ \\
\hline Ethnicity & & 0.421 & 1.000 & 0.675 \\
\hline Han & 238 & $266(52.8)$ & $131(26.0)$ & $118(23.4)$ \\
\hline Non-Han & 18 & $26(59.1)$ & $11(25.0)$ & 14(31.8) \\
\hline Marital status & & 0.051 & 0.063 & 1.000 \\
\hline $\begin{array}{l}\text { Unmarried } \\
\text { (Single\&Divorced) }\end{array}$ & 130 & 124(48.8) & $55(21.7)$ & $61(24.0)$ \\
\hline Married & 126 & $168(57.1)$ & $87(29.6)$ & $71(24.1)$ \\
\hline Education & & 0.672 & 0.303 & 1.000 \\
\hline College or lower & 76 & $97(56.1)$ & $57(32.9)$ & $35(20.2)$ \\
\hline Bachelor & 151 & 163(51.9) & $70(22.3)$ & $81(25.8)$ \\
\hline Master or above & 29 & $32(52.5)$ & $15(24.6)$ & $16(26.2)$ \\
\hline BMI & & 0.982 & 1.000 & 1.000 \\
\hline Lower than normal $(<18.5)$ & 44 & $49(52.7)$ & $22(23.7)$ & $23(24.7)$ \\
\hline Normal $(18.5-<23)$ & 128 & 145(53.1) & $80(29.3)$ & $59(21.6)$ \\
\hline Overweight $(23-<25)$ & 38 & $47(55.3)$ & $22(25.9)$ & $20(23.5)$ \\
\hline Obese $(\geq 25)$ & 46 & $51(52.6)$ & 18(18.6) & $30(30.9)$ \\
\hline
\end{tabular}

significantly differ with title for either doctors or nurses. Seniority and work arrangement had no effect on the prevalence of headache, including migraine and $\mathrm{TTH}$, in doctors or nurses.

We investigated whether the number of night shifts per month affected the prevalence of headache by grouping both doctors and nurses according to whether they worked more or less than the median of six (see
Table 5). Doctors who worked more than six night-shifts were significantly more likely to suffer both types of headache than those who worked fewer than six nightshifts (migraine: $27.7 \%$ v.s. $21.2 \%$; TTH: $27.7 \%$ v.s. $16.5 \%)$. Nurses who worked more than six night-shifts were significantly more likely to experience migraine headaches than those who worked fewer than six nightshifts $(37.8 \%$ v.s. $18.8 \%)$; however, the prevalence of

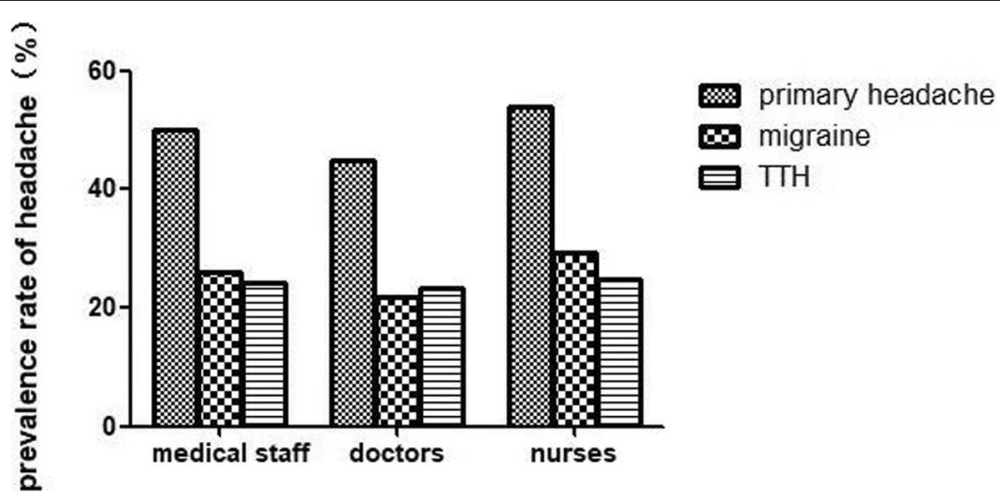

Fig. 1 Comparison of the prevalence of different types of headaches among medical staff, doctors and nurses 
Table 2 Prevalence of migraine and Tension-type headache among doctors and nurses of different genders

\begin{tabular}{|c|c|c|c|c|c|c|c|c|}
\hline \multirow[t]{3}{*}{ Variable } & \multicolumn{4}{|l|}{ Doctors } & \multicolumn{4}{|l|}{ Nurses } \\
\hline & \multirow{2}{*}{$\begin{array}{l}\text { Non- } \\
\text { headache N }\end{array}$} & Total headahe & Migraine & TTH & \multirow{2}{*}{$\begin{array}{l}\text { Non- } \\
\text { headache N }\end{array}$} & \multirow{2}{*}{$\begin{array}{l}\text { Total headache } \\
\mathrm{N}(\%) P\end{array}$} & \multirow{2}{*}{$\begin{array}{l}\text { Migraine } \\
N(\%) P\end{array}$} & \multirow{2}{*}{$\begin{array}{l}\mathrm{TTH} \\
\mathrm{N}(\%) P\end{array}$} \\
\hline & & $\mathrm{N}(\%) P$ & $\mathrm{~N}(\%) P$ & $\mathrm{~N}(\%) P$ & & & & \\
\hline Total & 127 & $113(47.1)$ & $52(21.7)$ & $56(23.3)$ & 129 & 179(58.1) & $90(29.2)$ & $76(24.7)$ \\
\hline Sex & & 0.193 & 0.002 & 0.712 & & 0.409 & 0.241 & 1.000 \\
\hline male & 78 & $60(43.5)$ & 19(13.8) & $36(26.1)$ & 4 & $2(33.3)$ & $0(0)$ & $2(33.3)$ \\
\hline female & 49 & $53(52.0)$ & $33(32.4)$ & 20(19.6) & 125 & $177(58.6)$ & $90(29.8)$ & $74(24.5)$ \\
\hline
\end{tabular}

TTH did not significantly differ with the frequency of night shift work.

The above factors were analysed by multivariate logistic regression (Tables 6 and 7), which showed that being female and working in other specialties remained independent risk factors for migraine in doctors. Female doctors were more than twice as likely as male doctors to experience migraine headaches, and doctors in other specialties were more likely to suffer migraines than doctors in the internal medicine and surgical departments. In nurses, being married and holding a senior job title remained independent risk factors for headaches overall, as did being married for migraine and having a senior job title for migraine and TTH. Nurses in the surgical department were more likely to suffer migraines than those in internal medicine. Nurses in other specialties were more likely to suffer migraines than internal medicine nurses, but there was no significant difference.

Among the doctors, sex and specialty were not risk factors for TTH in the multivariate logistic regression analysis, and age, nationality, marital status, education, BMI, seniority, title, and work arrangement were not identified as risk factors for either type of headache. Among the nurses, marital status and specialty were not identified as risk factors for TTH in the multivariate logistic regression analysis, and age, nationality, education,

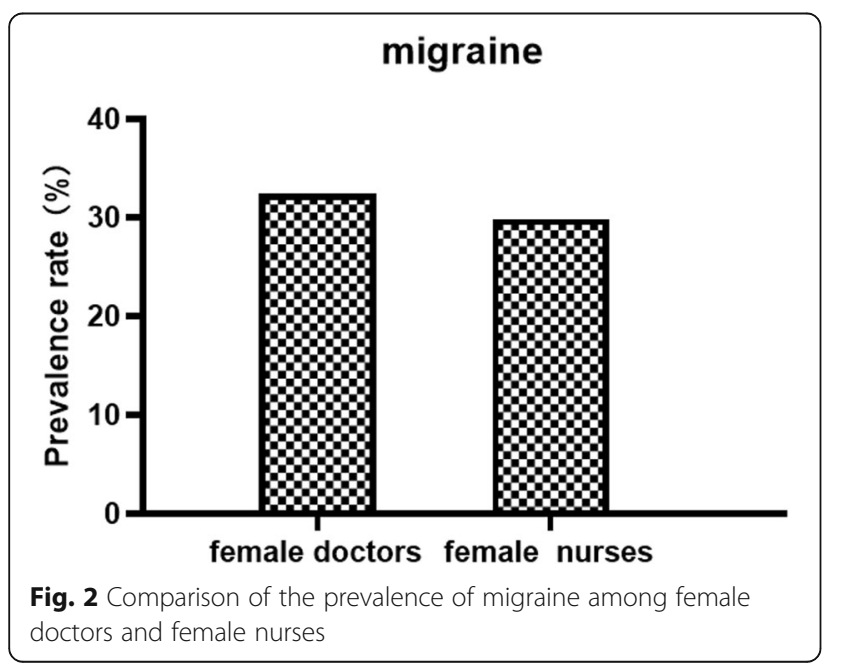

BMI, seniority, and work arrangement were not identified as risk factors for either type of headache.

\section{Discussion}

Primary headache disorders are important causes of disability and reduced quality of life, and hospital workers are at high risk [21-23]. We found that the 1-year prevalence of primary headache disorders among medical staff in Sanya, South China, was 50\% (migraine: 25.9\%; TTH: $24.1 \%$ ), which was significantly higher than the $23.8 \%$ (migraine: 9.3\%; TTH: $10.8 \%$ ) obtained in a populationbased study in mainland China [3]. The prevalence rate of hospital workers in previous literature was high, as Sokolovic reported a 3-month prevalence of 61\% [24], and Onwuekwe showed that the half-year prevalence was more than $70 \%$ [25]. There are two possible reasons for the difference. First, previous studies included nonclinical subjects (e.g., administrators and research staff). Second, a web-based survey adopted by previous studies may overrepresent persons with headache based on their willingness to respond.

Our nationwide population-based headache survey [3] suggested the prevalence of migraine was near the global average of $11 \%$, while $\mathrm{CDH}$ ( $1 \%$ v.s. $3 \%$ ) was less prevalent than it was worldwide. And $\mathrm{MOH}$ accounted for approximately $60 \%$ of $\mathrm{CDH}$. Our group's another study [26] showed $\mathrm{MOH}$ clinical profile $-\mathrm{MOH}$ in China was associated with lower educational level and annual income. A recent report [27] also suggested $\mathrm{MOH}$ was more common in the less well educated. Another study [15] recruited 1102 nurses among which only 10 respondents had two types of primary headache and only 2 were diagnosed with both $\mathrm{CDH}$ and $\mathrm{MOH}$, suggesting nursing staff had lower prevalence of $\mathrm{MOH}$ and $\mathrm{CDH}$ than the general population.

Similar to their results, among 548 respondents in our survey only 3 respondents were diagnosed with two types of primary headache, and 18 had other headaches, including neuralgia, $\mathrm{CDH}$, and unclassified headache. Only 1 nurse was diagnosed with $\mathrm{MOH}$, which may be related to the group characteristics of medical staff. Generally medical staff have higher average education level and annual income than general population. Moreover, as a special occupational group with certain medical 


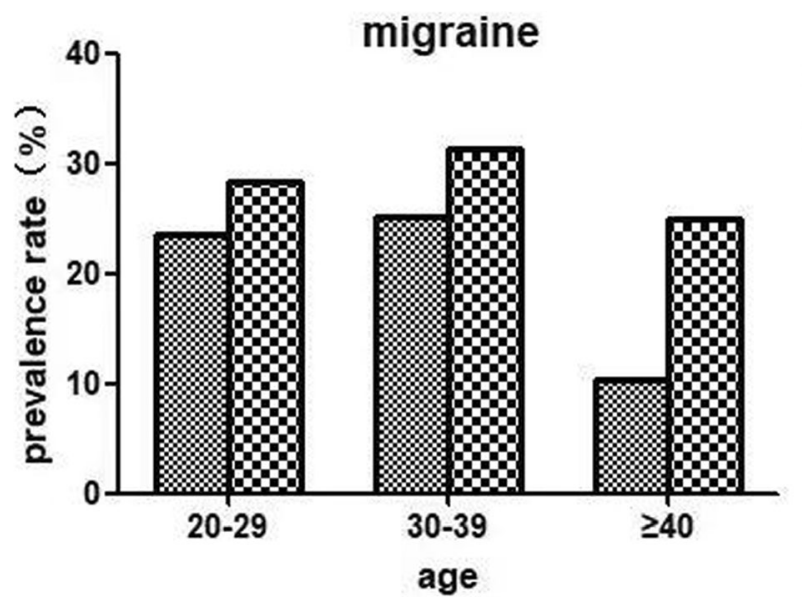

doctor

murse

Fig. 3 Prevalence of migraine among doctors and nurses by age

knowledge and convenient medical conditions, they took medicine more rationally and timely, which could be the main reason for the lower prevalence of $\mathrm{MOH}$ and $\mathrm{CDH}$ among medical staff.

As mentioned above, through headache questionnaires, face-to-face interviews and subsequent telephone follow-ups, we carefully confirmed only 3 respondents were diagnosed with two types of primary headache among 548 respondents, which was in accordance with the findings of the Chinese population-based door-todoor survey and northern nursing staff surveys $[3,15]$. Of course, this may be associated with our small sample.

To the best of our knowledge, this study is the first to investigate the prevalence of primary headache disorders among doctors in mainland China (45\% had primary headache disorder: $21.7 \%$ had migraine, and $23.3 \%$ had TTH). Unexpectedly, few data were available regarding headache among doctors on PubMed. Doctors' headaches seemed to be ignored. Bartolini $M$ reported that doctors were generally not more sensitised to problematic headache than the general population and tended to avoid evaluation by their general practitioner [28]. According to a survey of neurologists in Australia and New Zealand, 65.9\% of neurologists had a personal history of migraine. This finding suggested significant under-recognition of migraine among non-neurologists [29]. In the future, headache disorder education should target interventions to raise awareness of cephalalgia disorders in populations of doctors.

When the prevalence of headache among nurses in Sanya, South China was analysed separately, we found a $53.9 \%$ prevalence of primary headache, including a $29.2 \%$ prevalence of migraine and a $24.7 \%$ prevalence of TTH. Compared with North China (where the prevalence rates were $45.3,14.8$, and $26.2 \%$ for primary

\section{TTH}

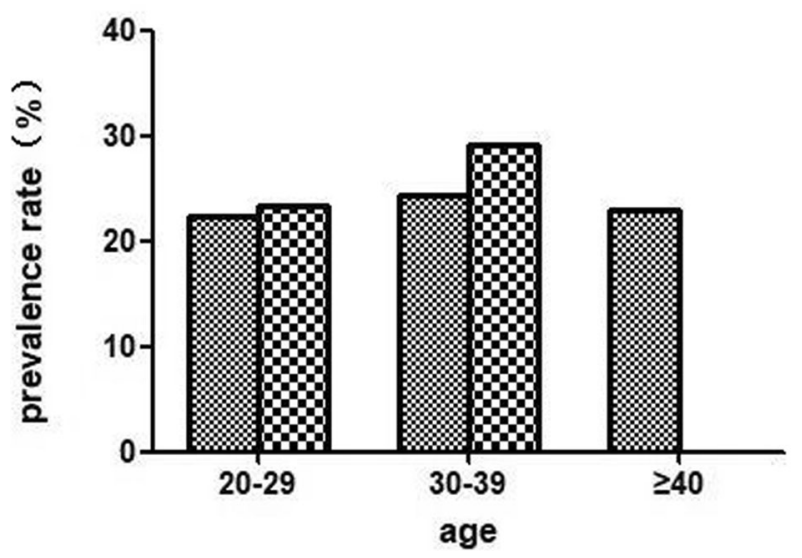

Fig. 4 Prevalence of $\mathrm{TTH}$ among doctors and nurses by age 
Table 3 The occupational characteristics comparisons between different types of headache and non-headache among doctors

\begin{tabular}{|c|c|c|c|c|}
\hline \multirow[t]{2}{*}{ Variable } & \multirow{2}{*}{$\begin{array}{l}\text { Non- } \\
\text { headache } \\
\mathrm{N}\end{array}$} & Total headache & Migraine & $\mathrm{TTH}$ \\
\hline & & $\mathrm{N}(\%) P$ & $N(\%)$ Bonferroni $P$ & $\mathrm{~N}(\%)$ Bonferroni $P$ \\
\hline Total & 127 & $113(47.1)$ & $52(21.7)$ & $56(23.3)$ \\
\hline Specialty & & 0.505 & 0.786 & 1.000 \\
\hline Internal Medicine & 77 & $61(44.2)$ & $28(20.3)$ & $31(22.5)$ \\
\hline Surgical Department & 37 & $36(49.3)$ & 14(19.2) & $20(27.4)$ \\
\hline Others & 13 & 16(55.2) & $10(34.5)$ & $5(17.2)$ \\
\hline Seniority (year) & & 0.945 & 1.000 & 1.000 \\
\hline$<5$ or 7 & 59 & $53(47.3)$ & $27(24.1)$ & $24(21.4)$ \\
\hline$\geq 5$ or 7 & 68 & $60(46.9)$ & 25(19.5) & $32(25.0)$ \\
\hline Title & & 0.136 & 0.222 & 1.000 \\
\hline Junior & 64 & $65(50.4)$ & $33(25.6)$ & $29(22.5)$ \\
\hline Senior & 32 & $32(50.0)$ & 14(21.9) & 17(26.6) \\
\hline Advanced & 31 & 16(34.0) & $5(10.6)$ & 10(21.3) \\
\hline Work arrangement & & 0.419 & 0.249 & 1.000 \\
\hline Day-shift & 35 & 26(42.6) & $8(13.1)$ & 16(26.2) \\
\hline Rotating-shift & 92 & $87(48.6)$ & $44(24.6)$ & $40(22.3)$ \\
\hline
\end{tabular}

headache, migraine and TTH, respectively) [15], the prevalence of TTH was similar, while migraine was more prevalent in South China. Geographical factors may be one explanation for the divergence. Sanya, located in the southernmost part of Hainan Island, is an international tourist city with a tropical maritime monsoon climate and plenty of sunlight. According to Tai MS, tropical weather can influence all types of trigger factors for migraine, and sunlight was a particularly common trigger factor in the equatorial and tropical regions of Asia [16].
Wang J reported that sunlight was one of the most common triggers for migraineurs in China [30].

Our study indicated that the prevalence of migraine in male doctors was lower than in female doctors. This result was consistent with the normal epidemiology of migraine, which was more common among women than among men [31]. However, female doctors seemed to have a higher prevalence of migraine than female nurses did. Chinese doctors must confront a large number of patients every day and perform scientific research to

Table 4 The occupational characteristics comparisons between different types of headache and non-headache among nurses

\begin{tabular}{lllll}
\hline Variable & $\begin{array}{l}\text { Non- } \\
\text { headache }\end{array}$ & Total headache & Migraine & THH \\
& $N$ & $N(\%) P(\%)$ Bonferroni $P$ & N(\%) Bonferroni $P$ \\
\hline Total & 129 & $179(58.1)$ & $90(29.2)$ & $76(24.7)$ \\
Specialty & & 0.073 & 0.033 & 1.000 \\
Internal Medicine & 72 & $77(51.7)$ & $32(21.5)$ & $39(26.2)$ \\
Surgical Department & 50 & $86(63.2)$ & $49(36.0)$ & $31(22.8)$ \\
Others & 7 & $16(69.6)$ & $9(39.1)$ & $6(26.1)$ \\
Seniority (year) & & 0.192 & 0.777 & 0.579 \\
$<5$ or 7 & 63 & $74(54.0)$ & $37(27.0)$ & $30(21.9)$ \\
$\geq 5$ or 7 & 66 & $105(61.4)$ & $53(31.0)$ & $46(26.9)$ \\
Title & & 0.002 & 0.450 & 0.000 \\
Junior & 70 & $65(48.1)$ & $38(28.1)$ & $21(15.6)$ \\
Senior & 45 & $99(68.8)$ & $43(29.9)$ & $49(34.0)$ \\
Advanced & 14 & $15(51.7)$ & $9(31.0)$ & $6(20.7)$ \\
Work arrangement & & 0.734 & 1.000 & 1.000 \\
Day-shift & 28 & $36(56.3)$ & $20(31.3)$ & $15(23.4)$ \\
Rotating-shift & 101 & $143(58.6)$ & $70(28.7)$ & $61(25.0)$ \\
\hline
\end{tabular}


Table 5 The impact of number of night shifts per month on the prevalence of different types of headache among doctors and nurses

\begin{tabular}{|c|c|c|c|c|c|c|c|c|c|c|c|c|}
\hline & \multicolumn{6}{|l|}{ Doctors } & \multicolumn{6}{|l|}{ Nurses } \\
\hline & $\begin{array}{l}\text { Total } \\
\text { headache }\end{array}$ & $\begin{array}{l}\text { OR } \\
(95 \% \text { Cl) }\end{array}$ & Migraine & $\begin{array}{l}\text { OR } \\
(95 \% \mathrm{Cl})\end{array}$ & TTH & $\begin{array}{l}\text { OR } \\
(95 \% \mathrm{Cl})\end{array}$ & $\begin{array}{l}\text { Total } \\
\text { headache }\end{array}$ & $\begin{array}{l}\text { OR } \\
(95 \% \mathrm{Cl})\end{array}$ & Migraine & $\begin{array}{l}\text { OR } \\
(95 \% \mathrm{Cl})\end{array}$ & $T \mathrm{TH}$ & $\begin{array}{l}\text { OR } \\
(95 \% \mathrm{Cl})\end{array}$ \\
\hline & $\begin{array}{l}\text { Prevalence } \\
\text { (\%) }\end{array}$ & & $\begin{array}{l}\text { Prevalence } \\
\text { (\%) }\end{array}$ & & $\begin{array}{l}\text { Prevalence } \\
\text { (\%) }\end{array}$ & & $\begin{array}{l}\text { Prevalence } \\
(\%)\end{array}$ & & $\begin{array}{l}\text { Prevalence } \\
(\%)\end{array}$ & & $\begin{array}{l}\text { Prevalence } \\
\text { (\%) }\end{array}$ & \\
\hline $\begin{array}{l}\text { Night shift } \\
\text { number }\end{array}$ & & $\begin{array}{l}1.94 \\
(1.07-3.52)\end{array}$ & & $\begin{array}{l}1.80 \\
(0.87-3.72)\end{array}$ & & $\begin{array}{l}2.31 \\
(1.07-4.98)\end{array}$ & & $\begin{array}{l}1.67 \\
(1.00-2.80)\end{array}$ & & $\begin{array}{l}2.72 \\
(1.43-5.15)\end{array}$ & & $\begin{array}{l}0.99 \\
(0.52-1.87)\end{array}$ \\
\hline$<6$ & $34 / 85(40.0)$ & & $18 / 85(21.2)$ & & $\begin{array}{l}14 / 85 \\
(16.5)\end{array}$ & & $61 / 117(52.1)$ & & 22/117(18.8) & & $34 / 117(29.1)$ & \\
\hline$\geq 6$ & $53 / 94(56.4)$ & & $26 / 94(27.7)$ & & $\begin{array}{l}26 / 94 \\
(27.7)\end{array}$ & & $82 / 127(64.6)$ & & 48/127(37.8) & & 27/127(21.3) & \\
\hline
\end{tabular}

improve their knowledge. They were under great pressure and were very fatigued, which were triggers of migraine [32]. Strained doctor-patient relationships might also be responsible for this phenomenon.

Medical staff, a specific occupational group, were characterised by frequent shift work, especially night shifts. Night shift work had a series of well-known consequences, including sleep deprivation, sleep disturbances and irregular daily routines, which were considered triggers of migraine and TTH [33, 34]. The study in North China reported a higher prevalence of migraine among shift-working nurses [15]. Similar to previous findings, our results demonstrated that medical staff who worked a greater number of night shifts $(\geq 6)$ had an increased prevalence of migraine. We found that working a relatively higher number of night shifts was associated with higher odds of TTH onset in doctors, but not in nurses. This phenomenon may be explained by the fact that doctors sit longer than nurses and that sitting causes an excessive forward head position or forward head posture (FHP). Fernández-de-Las-Peñas $\mathrm{C}$ found that FHP was associated with chronic tension-type headache (CTTH). His study suggested that shortened, contracted head and neck muscles associated with FHP may contribute to the development or perpetuation of TTH $[35,36]$. However, further studies are required to investigate this possibility.

Multivariate analysis revealed that surgical nurses were more likely to have migraine than internal medicine nurses.
Long and continuous working hours, missed meals, odours in the operating room and other common triggers of migraine may be responsible for the difference [37]. However, surgeons who worked in the same environment as the surgical nurses and experienced high stress levels during operations, were not more likely to have migraines than physicians. This may be attributable to a strong ability to manage stress and suggested that sex hormone may be a leading cause of migraine instead of other factors because almost all surgeons in China were male. In our study, a senior job title was significantly associated with a greater prevalence of headache (both TTH and migraine) in nurses, indicating that occupational factors affected the prevalence of headache. Nurses with senior titles tended to be married and had the dual responsibilities of mothers and wives. They must shoulder the burden of family and carry a high workload. In addition to clinical work, they were also responsible for management and teaching activities. However, the small number of participants with advanced titles may have affected the reliability of the results.

\section{Limitations}

Our study had several limitations. First, the sample size was small, which may affect the accuracy of the results. It was not possible to further investigate the prevalence of and risk factors associated with subtypes of migraine and TTH. Second, the role of other factors, such as anxiety, depression, noise exposure, alcohol use and changes

Table 6 Multivariable adjusted odds ratios (95\% confidence interval) for total headache, migraine, and tension-type headache (TTH) among doctors

\begin{tabular}{llll}
\hline & Total headache & Migraine & $T H$ \\
\hline Sex & & & Reference \\
Male & Reference & Reference & $1.088(0.493-2.402)$ \\
Female & $1.477(0.782-2.789)$ & $2.314(1.005-5.326)^{*}$ & Reference \\
Specialty & & & $1.275(0.586-2.771)$ \\
Internal Medicine & Reference & Reference & $1.564(0.630-3.877)$ \\
Surgical Department & $1.364(0.720-2.586)$ & $3.223(1.122-9.259)^{*}$ & $1.051(0.308-3.586)$ \\
Others & $1.932(0.814-4.586)$ & &
\end{tabular}


Table 7 Multivariable adjusted odds ratios (95\% confidence interval) for total headache, migraine, and tension-type headache (TTH) among nurses

\begin{tabular}{|c|c|c|c|}
\hline & Total headache & Migraine & $\mathrm{TTH}$ \\
\hline \multicolumn{4}{|l|}{ Marital status } \\
\hline Unmarried/Divorced & Reference & Reference & Reference \\
\hline Married & $2.737(1.421-5.271)^{* *}$ & $3.728(1.640-8.472)^{* *}$ & 1.855(0.839-4.099) \\
\hline \multicolumn{4}{|l|}{ Specialty } \\
\hline Internal Medicine & Reference & Reference & Reference \\
\hline Surgical Department & $1.463(0.886-2.418)$ & $1.910(1.036-3.521)^{*}$ & $1.018(0.536-1.936)$ \\
\hline Others & $2.180(0.797-5.962)$ & $2.607(0.841-8.083)$ & $1.352(0.375-4.876)$ \\
\hline \multicolumn{4}{|l|}{ Title } \\
\hline Junior & Reference & Reference & Reference \\
\hline Senior & $3.044(1.530-6.057)^{* *}$ & $2.294(1.012-5.199)^{*}$ & $4.695(1.866-11.808)^{* *}$ \\
\hline Advanced & $1.720(0.527-5.616)$ & $1.966(0.487-7.933)$ & $2.006(0.422-9.524)$ \\
\hline
\end{tabular}

${ }^{*} P<0.05,{ }^{* *} P<0.01$

in the weather, which may potentially influence the prevalence of headache, should be explored in future studies. In addition, the recall bias arising from participants' answers to occurrences and characteristics of headache in the past year may have affected the reliability of survey data, and prospective diary studies should be encouraged.

\section{Conclusion}

Our study shows that the prevalence of primary headache disorders (including migraine and $\mathrm{TTH}$ ) in both nurses and doctors is higher than that of the general population in South China. The special geographical location of Sanya could be responsible for the difference in the prevalence of migraine between nurses in North and South China. Multiple factors associated with migraine and TTH among medical staff were verified, including sex and specialty for migraine in doctors; marital status, title and specialty for migraine in nurses; and job title for TTH in nurses. To improve the health of medical staff, headache education and strategies for managing these factors should be effectively implemented.

\section{Abbreviations}

$\mathrm{CDH}$ : Chronic daily headache; ICHD-3: International Classification of Headache Disorders, 3rd edition; $\mathrm{MOH}$ : Medication overuse headache; TTH: Tension type headache

\section{Acknowledgements}

We gratefully acknowledge the nurses and doctors who participated in this study.

\section{Authors' contributions}

Dr. WX was responsible for reviewing the literature and writing the manuscript. Dr. RL was responsible for data statistics. Dr. MH co-organized this survey. Dr. FC, TS and JX were regional leaders of this survey. DZ and $W N$ were responsible for issuing and recalling the questionnaires. Dr. RL and SY were the principal investigators who were responsible for study design, data analysis and interpretation, and revision of the manuscript. As cocorresponding author, Dr. RL and SY had full access to all the data in the study and had final responsibility for the decision to submit for publication. All authors read and approved the final manuscript.

\section{Funding}

This work was supported by the Hainan Sanya Medical and Health Technology Innovation Project (grant number 2016YW20) and the National Science Foundation of China (grants 81771180,81671077), Beijing Natural Science Foundation Essential Research Project Z170002, 15BJZ49.

Availability of data and materials

The datasets used and analyzed during the current study are available from the corresponding author on reasonable request.

\section{Ethics approval and consent to participate}

The ethics committee of the Chinese PLA General Hospital approved this study. All respondents were informed of the purpose of the study. Written informed consent was obtained from all participants.

Consent for publication

Not applicable.

\section{Competing interests}

The authors declare that they have no competing interests.

\section{Author details}

${ }^{1}$ International Headache Center, Department of Neurology, the First Medical Center, Chinese PLA General Hospital, Fuxing Road 28, Haidian District, Beijing 100853, China. 'Department of Laboratory Medicine, the First Medical Center, Chinese PLA General Hospital, Fuxing Road 28, Haidian District, Beijing 100853, China. ${ }^{3}$ Department of Neurology, Hainan Hospital of Chinese PLA General Hospital, Jianglin Road 28, Sanya 572013, China.

Received: 5 November 2019 Accepted: 9 January 2020

Published online: 14 January 2020

References

1. Lj S, Hagen K, Jensen R et al (2007) The global burden of headache: a documentation of headache prevalence and disability worldwide. Cephalalgia 27(3):193-210

2. (2018) Global, regional, and national burden of migraine and tension-type headache, 1990-2016: a systematic analysis for the Global Burden of Disease Study 2016. Lancet Neurol 17(11):954-976

3. Yu S, Liu R, Zhao G et al (2012) The prevalence and burden of primary headaches in China: a population-based door-to-door survey. Headache 52(4):582-591

4. Saylor D, Steiner TJ (2018) The global burden of headache. Semin Neurol 38(2):182-190 
5. (2016) Global, regional, and national disability-adjusted life-years (DALYs) for 315 diseases and injuries and healthy life expectancy (HALE), 1990-2015: a systematic analysis for the Global Burden of Disease Study 2015. Lancet 388(10053):1603-1658

6. (2016) Global, regional, and national incidence, prevalence, and years lived with disability for 310 diseases and injuries, 1990-2015: a systematic analysis for the Global Burden of Disease Study 2015. Lancet 388(10053):1545-1602

7. Delaruelle Z, Ivanova TA, Khan S et al (2018) Male and female sex hormones in primary headaches. J Headache Pain 19(1):117

8. Pinhas-Hamiel O, Frumin K, Gabis L et al (2008) Headaches in overweight children and adolescents referred to a tertiary-care center in Israel. Obesity (Silver Spring) 16(3):659-663

9. Straube A, Heinen F, Ebinger F (2013) von KR. Headache in school children: prevalence and risk factors. Dtsch Arztebl Int 110(48):811-818

10. Lebedeva ER, Kobzeva NR, Gilev DV, Olesen J (2016) Factors associated with primary headache according to diagnosis, sex, and social group. Headache 56(2):341-356

11. Friedman DI, De ver Dye T (2009) Migraine and the environment. Headache 49(6):941-952

12. Yu S, Liu R, Yang X et al (2012) Body mass index and migraine: a survey of the Chinese adult population. J Headache Pain 13(7):531-536

13. Luo N, Qi W, Tong W et al (2014) Prevalence and burden of headache disorders in two neighboring provinces of China. J Clin Neurosci 21(10): 1750-1754

14. Huang $\mathrm{Q}$, Yu $\mathrm{H}$, Zhang $\mathrm{N}$ et al (2019) Body mass index and primary headache: a hospital-based study in China. Biomed Res Int 2019:4630490

15. Wang Y, Xie J, Yang F et al (2015) The prevalence of primary headache disorders and their associated factors among nursing staff in North China. J Headache Pain 16:4

16. Tai MS, SXE Y, Lim TC, Pow ZY, Goh CB (2019) Geographical differences in trigger factors of tension-type headaches and migraines. Curr Pain Headache Rep 23(2):12

17. Li W, Bertisch SM, Mostofsky E, Buettner C, Mittleman MA (2019) Weather, ambient air pollution, and risk of migraine headache onset among patients with migraine. Environ Int 132:105100

18. Yu SY, Cao XT, Zhao G et al (2011) The burden of headache in China: validation of diagnostic questionnaire for a population-based survey. J Headache Pain 12(2):141-146

19. Classification and diagnostic criteria for headache disorders, cranial neuralgias and facial pain (1988) Headache Classification Committee of the International Headache Society. Cephalalgia 8(Suppl 7):1-96

20. Yancey JR, Sheridan R, Koren KG (2014) Chronic daily headache: diagnosis and management. Am Fam Physician 89(8):642-648

21. Hughes MD, Wu J, Williams TC et al (2013) The experience of headaches in health care workers: opportunity for care improvement. Headache 53(6): 962-969

22. Kuo WY, Huang CC, Weng SF et al (2015) Higher migraine risk in healthcare professionals than in general population: a nationwide population-based cohort study in Taiwan. J Headache Pain 16:102

23. Steiner TJ, Stovner LJ, Vos T (2016) GBD 2015: migraine is the third cause of disability in under 50s. J Headache Pain 17(1):104

24. Sokolovic E, Riederer F, Szucs T, Agosti R, Sándor PS (2013) Self-reported headache among the employees of a Swiss university hospital: prevalence, disability, current treatment, and economic impact. J Headache Pain 14:29

25. Onwuekwe I, Onyeka T, Aguwa E, Ezeala-Adikaibe B, Ekenze O, Onuora E (2014) Headache prevalence and its characterization amongst hospital workers in Enugu, South East Nigeria. Head Face Med 10:48

26. Dong Z, Chen X, Steiner TJ et al (2015) Medication-overuse headache in China: clinical profile, and an evaluation of the ICHD-3 beta diagnostic criteria. Cephalalgia 35(8):644-651

27. Luvsannorov O, Tsenddorj B, Baldorj D et al (2019) Primary headache disorders among the adult population of Mongolia: prevalences and associations from a population-based survey. J Headache Pain 20(1):114

28. Bartolini M, Viticchi G, Falsetti L et al (2014) Migraine in health workers: working in a hospital can be considered an advantage. Neurol Sci 35(Suppl 1):27-29

29. Yeh WZ, Blizzard L, Taylor BV (2018) What is the actual prevalence of migraine. Brain Behav 8(6):e00950

30. Wang J, Huang Q, Li N, Tan G, Chen L, Zhou J (2013) Triggers of migraine and tension-type headache in China: a clinic-based survey. Eur J Neurol 20(4):689-696
31. Vetvik KG, MacGregor EA (2017) Sex differences in the epidemiology, clinical features, and pathophysiology of migraine. Lancet Neurol 16(1):76-87

32. Peroutka SJ (2014) What turns on a migraine? A systematic review of migraine precipitating factors. Curr Pain Headache Rep 18(10):454

33. Fernández-de-Las-Peñas C, Fernández-Muñoz JJ, Palacios-Ceña M, ParásBravo P, Cigarán-Méndez M, Navarro-Pardo E (2018) Sleep disturbances in tension-type headache and migraine. Ther Adv Neurol Disord 11: 1756285617745444

34. Jensen HI, Larsen JW, Thomsen TD (2018) The impact of shift work on intensive care nurses' lives outside work: a cross-sectional study. J Clin Nurs 27(3-4):e703-e709

35. Fernández-de-las-Peñas C, Alonso-Blanco C, Cuadrado ML, Pareja JA (2006) Forward head posture and neck mobility in chronic tension-type headache: a blinded, controlled study. Cephalalgia. 26(3):314-319

36. Fernández-de-Las-Peñas C, Cuadrado ML, Pareja JA (2007) Myofascial trigger points, neck mobility, and forward head posture in episodic tension-type headache. Headache 47(5):662-672

37. Pavlovic JM, Buse DC, Sollars CM, Haut S, Lipton RB (2014) Trigger factors and premonitory features of migraine attacks: summary of studies. Headache 54(10):1670-1679

\section{Publisher's Note}

Springer Nature remains neutral with regard to jurisdictional claims in published maps and institutional affiliations.
Ready to submit your research? Choose BMC and benefit from:

- fast, convenient online submission

- thorough peer review by experienced researchers in your field

- rapid publication on acceptance

- support for research data, including large and complex data types

- gold Open Access which fosters wider collaboration and increased citations

- maximum visibility for your research: over $100 \mathrm{M}$ website views per year

At BMC, research is always in progress.

Learn more biomedcentral.com/submissions 